Note

\section{Variation in Rheological Properties of Konjac Gel with the Corm Cultivar}

\author{
Kenji MaekaJi and Daizo Kawamura \\ Hiroshima Prefectural Food Technological \\ Research Center, 12-70 Hijiyamahonmachi, \\ Minami-ku, Hiroshima 730, Japan
}

Received February 19,1985

It is well known that the rheological properties of konjac gel depend essentially on the physico-chemical properties $^{1)}$ of the konjac flour which is obtained from corms of Amorphopallus konjac C. Koch. As the physicochemical properties of konjac flour seem to be determined by the origin ${ }^{25}$ ) of the corm to a great extent, the rheological properties of a gel may vary with the corm cultivar.

In connection with this problem, it has been reported ${ }^{2,6)}$ that the native variety is superior to some cultivars in gel quality (for example, gel strength or breaking deformation), and others ${ }^{7)}$ have reported that this relation is not always valid. Thus, because of this controversy, this problem has to be solved without delay not only from the academic standpoint but also from the practical point of view.

The authors attempted to demonstrate the variation in rheological properties of gels with the cultivar by means of stress-relaxation examination.

Samples of konjac flour were obtained from the corms of four cultivars, i.e., Zairai (native), Shina (Chinese), Harunakuro and Akagiohdama. These corms, which were all harvested in Gunma prefecture, were industrially processed in the same manner at a specified plant.
The methods for preparation of the gels and stressrelaxation examination were essentially the same as those mentioned previously. ${ }^{89}$ Konjac paste mixed with sodium phosphate was gelatinized by heating at $80^{\circ} \mathrm{C}$ after deairing by centrifugation. The final concentration of konjac flour in each gel was adjusted accurately to $2.5 \%$ taking into account the moisture content of the raw material. The gel specimen $(\phi 28 \times 30 \mathrm{~mm})$ was subjected to stressrelaxation which was carried out at $30^{\circ} \mathrm{C}$ using an Autograph equipped with a compressing attachment (Shimadzu Seisakusho Co., 1 M-100). The stressrelaxation curve obtained was analysed with a mechanical model composed of three Maxwell elements in parallel, and the elastic modulus $\left(E_{\mathrm{i}}\right)$ and relaxation time $\left(\tau_{\mathrm{i}}\right)$ were obtained.

In order to determine the squeezed water $\left(W_{\mathrm{sq}}\right)$ liberated by syneresis, the weight of a gel specimen was checked before and after the experiment.

Statistical analysis ( $t$-test) of the obtained data was performed for confirmation of a significant difference between any two cultivars. Five percent was taken as the standard level of significance.

As supplemental data, apparent viscosity $\left(\eta_{\mathrm{a}}\right)$ and gel forming ability $(\tan \theta)^{10)}$ of the konjac sol were measured with an Amylograph (Brabender Co., VA-1) in addition to the determination of moisture and ash contents of the konjac flour. In these cases, however, statistical analysis was omitted, because the measurements were not repeated more than twice.

The results of stress-relaxation examination and the quantity of squeezed water are shown in Table I. It can be seen that the rheological properties of the gels are dominated by those of the 1st Maxwell element also ${ }^{8)}$ in this case. This indicates that the overall rheological properties of a gel are practically represented by those assigned to this element. Because of this, $E_{1}$ and $\tau_{1}$ were used as the measures for estimation of differences.

The magnitude of $E_{1}$ (as well as $E_{0}$ ) of each gel was in the order of Zairai $>$ Harunakuro $>$ Shina $>$ Akagi-

Table I. Variation in Physical Properties of Konjac Gel with the Cultivar

\begin{tabular}{|c|c|c|c|c|}
\hline Cultivar & Zairai & Shina & Harunakuro & Akagiohdama \\
\hline $\begin{array}{l}\text { Measurement } \\
\text { (time) }\end{array}$ & 6 & 4 & 4 & 3 \\
\hline$\left(\mathrm{dyn} / \mathrm{cm}^{2}\right)$ & $(12.0 \pm 1.07) \times 10^{4}$ & $(8.98 \pm 0.64) \times 10^{4}$ & $(10.4 \pm 0.78) \times 10^{4}$ & $(8.30 \pm 0.26) \times 10^{4}$ \\
\hline$\left(\mathrm{dyn} / \mathrm{cm}^{2}\right)$ & $(9.47 \pm 0.75) \times 10^{4}$ & $(6.90 \pm 0.56) \times 10^{4}$ & $(7.93 \pm 0.54) \times 10^{4}$ & $(6.60 \pm 0.29) \times 10^{4}$ \\
\hline$\left(\mathrm{dyn} / \mathrm{cm}^{2}\right)$ & $(1.78 \pm 0.38) \times 10^{4}$ & $(1.45 \pm 0.26) \times 10^{4}$ & $(1.73 \pm 0.91) \times 10^{4}$ & $(1.00 \pm 0.08) \times 10^{4}$ \\
\hline$\left(\mathrm{dyn} / \mathrm{cm}^{2}\right)$ & $(7.83 \pm 1.46) \times 10^{3}$ & $(6.25 \pm 1.78) \times 10^{3}$ & $(7.50 \pm 2.18) \times 10^{3}$ & $(4.33 \pm 0.47) \times 10^{3}$ \\
\hline$(\mathrm{hr})$ & $9.26 \pm 1.30$ & $11.67 \pm 0.94$ & $9.07 \pm 1.32$ & $12.62 \pm 1.69$ \\
\hline (hr) & $(6.95 \pm 0.60) \times 10^{-1}$ & $1.03 \pm 0.13$ & $(8.73 \pm 0.21) \times 10^{-1}$ & $(6.63 \pm 0.79) \times 10^{-1}$ \\
\hline (hr) & $(8.67 \pm 1.25) \times 10^{-2}$ & $(7.50 \pm 0.87) \times 10^{-2}$ & $(8.50 \pm 2.60) \times 10^{-2}$ & $(7.67 \pm 0.90) \times 10^{-2}$ \\
\hline$W_{\mathrm{sq}}(\%)$ & $5.50 \pm 0.28$ & $5.28 \pm 0.43$ & $5.68 \pm 0.29$ & $4.90 \pm 0.08$ \\
\hline
\end{tabular}

$E_{\mathrm{i}}$, elastic modulus; $\tau_{\mathrm{i}}$, relaxation time; $W_{\text {sq }}$, squeezed water. 
ohdama. Statistical analysis showed that the relations of Zairai $>$ Harunakuro, Zairai $>$ Shina, Zairai $>$ Akagiohdama and Harunakuro $>$ Akagiohdama are significant. Thus, Zairai is the largest of the four. Harunakuro is larger than Akagiohdama, though smaller than Zairai. Shina is in between Harunakuro and Akagiohdama, though the difference from the other two is statistically insignificant. The relations mentioned above can be summarized as follows;

\section{Zairai $>$ Harunakuro $\sim$ Shina $\sim$ Akagiohdama}

where $>$ signifies a significant difference and $\sim$ an insignificant one.

The magnitude of $\tau_{1}$ was in the order of Akagiohdama $>$ Shina $>$ Zairai $>$ Harunakuro. By means of statistical analysis, it was shown that the relation of Akagiohdama $>$ Zairai, Akagiohdama $>$ Harunakuro, Shina $>$ Zairai and Shina $>$ Harunakuro are significant. Thus, the samples can be classified into two groups, i.e., (Akagiohdama + Shina) and (Zairai+Harunakuro). Of course, any one of the former is larger than any one of the latter in value. The relation can be summarized as follows;

\section{Akagiohdama $\sim$ Shina $>$ Zairai $\sim$ Harunakuro}

The quantity of squeezed water, which was shown previously ${ }^{8)}$ to be related closely to $\tau_{1}$, was in the order of Harunakuro $>$ Zairai $>$ Shina $>$ Akagiohdama. Although any combination other than Harumakuro $>$ Akagiohdama and Zairai $>$ Akagiohdama was not significant statistically, the order was in the reverse of that of $\tau_{1}$ at least.

From the results mentioned above, the characteristics of each cultivar in regard to gel quality may be summed up as follows. Zairai is the most elastic, but liable to be deformed by stress that accompanies syneresis. Akagiohdama is markedly different to Zairai. Harunakuro is almost the same as Zairai except for being less elastic to some exent. Shina is closer to Akagiohdama than to Zairai.

The qualities of the konjac flours and konjac sols are shown in Table II. In respect to the moisture content, Zairai and Shina were different from the other two to a small extent. The difference in this content seems irrelevant as to the differences in gel properties, as the final moisture content was corrected when the gel was prepared. Little fluctuation was detected in the ash content:

The order of $\eta_{\mathrm{a}}$ was Zairai $>$ Harunakuro $>$ Akagiohdama $>$ Shina, and that of $\tan \theta$ Shina $=$ Akagiohdama $>$ Harunakuro $>$ Zairai. The former roughly coincides with that of $E_{1}$. The latter, on the other hand,
Table II. Properties of Konjac Flours

Cultivar Zairai Shina Harunakuro Akagiohdama

\begin{tabular}{lrrrr}
\hline Moisture (\%) & 11.37 & 9.25 & 9.74 & 10.31 \\
Ash (\%) & 6.06 & 5.89 & 6.66 & 6.02 \\
$\eta_{\mathrm{a}}(\mathrm{BU})$ & 703 & 674 & 699 & 695 \\
$\tan \theta$ & 1.24 & 1.32 & 1.29 & 1.32 \\
\hline
\end{tabular}

is almost the reverse. It is rather close to that of $\tau_{1}$. Therefore, the difference in elasticity of gels was roughly estimated with the $\eta_{\mathrm{a}}$ value, but not with $\tan \theta$ at least. The relation between $\tan \theta$ and rheological properties of gels became complicated in this examination contrary to expectation. ${ }^{10)}$

Thus, the difference in rheological properties of konjac gels among the cultivars was demonstrated tentatively by stress-relaxation examination, though it was not supported by the difference in quality of the konjac flours. To clarify the relation between the quality of the gel and the cultivar more, however, it is necessary to elucidate the influence of such factors as age, the harvest area, management practice in cultivation etc., of the corms on the quality of the flour and gel in addition. More detailed work on this problem is in progress.

\section{REFERENCES}

1) S. Okimasu, "Konnyaku no Kagaku," ed. by $\mathrm{S}$. Okimasu, Keisuisha, Hiroshima, 1983, pp. 94, 134.

2) N. Kishida and S. Okimasu, J. Home Econ. Japan, 19, 406 (1968).

3) N. Sugiyama, H. Shimahara, T. Andoh, M. Takemoto and T. Kamata, Agric. Biol. Chem., 36, 1381 (1972).

4) N. Kishida and S. Okimasu, Agric. Biol. Chem., 42, 1645 (1978).

5) N. Kishida, Agric. Biol. Chem., 43, 2391 (1979).

6) H. Shimahara and Y. Shimizu, Nippon Shokuhin Kogyo Gakkaishi, 26, 299 (1979).

7) H. Tamura and K. Sakai, Rep. Agric. Forestry Products Inspection Inst. Tokyo, 3, 53 (1977).

8) K. Maekaji and D. Kawamura, Agric. Biol. Chem., 48, 227 (1984).

9) Y. Ohta and K. Maekaji, Nippon Nôgeikagaku Kaishi, 54, 741 (1980).

10) Y. Ohta and K. Maekaji, Bull. Hiroshima Food Res. Inst., 14, 23 (1977). 